\title{
O "traficante" não vai à escola: processos de esco- larização de adolescentes com envolvimento no tráfico de drogas
}

\section{Resumo}

\author{
Alex Sandro Gomes Pessoa \\ Universidade do Oeste Paulista \\ Renata Maria Coimbra \\ Universidade Estadual Paulista
}

Este artigo analisa o contexto escolar de adolescentes com histórico de envolvimento no tráfico de drogas, bem como explicita dados sobre as experiências educacionais em escolas regulares e àquelas frequentadas durante a aplicação de medidas socioeducativas. Trata-se de um estudo quanti-qualitativo que contou com a participação de 577 adolescentes e jovens $(M=16,01 ; D P=1,54)$, de ambos os sexos e que residem em três municípios de médio porte localizados no interior do estado de São Paulo. Foram utilizados dois questionários e um roteiro de entrevistas semiestruturado. Os resultados apontam um histórico de fracasso das instituições escolares na vida dos adolescentes com envolvimento no tráfico, marcado por reprovações, expulsões e falta de sentidos. Paradoxalmente, as experiências em escolas, inseridas em instituições de medidas socioeducativas, mostraram-se mais positivas e sugerem a possibilidade da ressignificação das trajetórias escolares. Tais achados abrem espaço para novos recortes investigativos e trazem implicações para o campo educacional.

Palavras-chave: Adolescência. Escola. Tráfico de drogas.

\section{The "drug dealer" does not go to school: educational trajectories of teena- gers with history of involvement in drug trafficking}

\section{Abstract}

This paper analyzes the school contexts of adolescents with history of involvement in drug trade, as well as present data regarding educational experiences in regular schools and schools within the correctional system. It refers a mixed-method study, including 577 adolescents and young people $(M=16,01 ; S D=1,54)$, both gender, and who were living in three medium-sized cities in the inner state of São Paulo, Brazil. We have used two questionnaires in the quantitative study and conducted semi-structured interviews with a small group. The findings show a history of failure of educational institutions in the teenagers' ' lives involved in drug trafficking, marked by abandonment and lack of personal meanings. Paradoxically, the experiences in the schools located in the correctional system were more positively evaluated and suggest the possibility of reframing the school trajectories. Such findings highlight new research questions and bring out implications for the educational field.

Keywords: Adolescence. School. Drug trafficking. 


\section{El "traficante" no va a la escuela: procesos de escolarización de ado- lescentes involucrados en el tráfico de drogas}

\section{Resumen}

Este artículo analiza el ambiente escolar de adolescentes con antecedentes de envolvimiento en el tráfico de drogas, al mismo tiempo muestra datos sobre las experiencias educacionales en escuelas regulares y escuelas frecuentadas durante la aplicación de medidas socioeducativas. Es un estudio cuantitativo-cualitativo en el que participaron 577 adolescentes y ióvenes ( $M=16.01$; DP $=1.54)$ de ambos sexos que viven en tres municipios medianos localizados en el interior del estado de Sao Paulo. Se usaron dos cuestionarios y una semiestructurada semi estructurada secuencia de entrevistas. Los resultados revelan una trayectoria de fracaso de las instituciones escolares en la vida de los adolescentes con antecedentes de envolvimiento en el tráfico de drogas, caracterizada por reprobaciones, expulsiones y falta de sentido. Paradóiicamente, las experiencias en escuelas injeridas en instituciones que aplican medidas socioeducativas resultaron más positivas y sugieren la posibilidad de dar una nueva orientación a las trayectorias escolares. Esto abre espacios para nuevos recortes investigativos y ofrecen implicaciones para el campo educacional.

Palabras clave: Adolescencia. Escuela. Tráfico de drogas.

\section{Introdução}

envolvimento de adolescentes no tráfico de drogas tem sido uma temática de interesse de pesquisadores no âmbito internacional (ALLEN; LO, 2012 ; SHOOK; VAUGHN; GOODKIND; JOHNSON, 2011 ; FLOYD; ALEXANDRE; HEDDEN; LAWSON; LATIMER; GILES, 2010) e no contexto brasileiro (ROCHA, 2015; MALVASI, 2012; FEFFERMANN, 2006). Conforme visualizado nesses trabalhos, diversos elementos podem explicar o envolvimento de adolescentes nessas atividades, como, por exemplo, processos discriminatórios de determinados grupos, questões étnicas que nutrem relações assimétricas, exposição das comunidades a múltiplos fatores de risco psicossocial, anseio pelo consumo de produtos fetichizados, entre outros.

Para compreender como é configurado o tráfico de drogas realizado por adolescentes, é necessário levar em consideração diversos aspectos, relacionados a questões macrossociais e de ordem subjetiva (ROCHA, 2013; 
O "traficante" não vai à escola: processos de escolarização de adolescentes com envolvimento no tráfico de drogas

GUITART, 201 11. As análises dessa conjuntura devem ser pautadas em concepções não estereotipadas e suficientemente abrangentes para captar dimensões mais próximas da realidade da população em questão.

Desse modo, em primeira instância, é fundamental desmistificar alguns tabus que perpassam o imaginário social sobre o envolvimento de adolescentes no tráfico de drogas. A adesão desse segmento, nessas atividades tidas como ilícitas, não é ao acaso (DOWDNEY, 2004), tampouco se pode afirmar que são pessoas desprovidas de valores morais ou, ainda, sujeitos que optam por um estilo de "vida fácil". É necessário compreender o atual modelo de organização social que estabelece relações assimétricas de poder, utiliza mecanismos exploratórios do ser humano e coisifica o outro para a manutenção de status e obtenção do poder. É no bojo dessas relações que o tráfico ganha espaço na vida de adolescentes.

Faria e Barros (2011) pontuam que, entre os aspectos que podem explicar o envolvimento de adolescentes no tráfico, além da escassez de oportunidades, podem ser citados a economia neoliberal, a busca por reconhecimento e o funcionamento de uma organização. Trata-se, segundo as autoras, de uma atividade altamente lucrativa, dentro da lógica do capital, 192 que permite a aquisição de um status social diferenciado e gestado por um sistema de funcionamento que solidifica leis próprias (ver também o trabalho de PESSOA, 2015).

Os dados divulgados no relatório produzido pelo Sistema Nacional de Atendimento Socioeducativo (SINASE, 2012) trazem um dimensionamento do número de adolescentes em cumprimento de medida socioeducativa por terem cometido algum tipo de ato infracional. $\bigcirc$ relatório mostra que, entre os anos de 2010 e 2012, houve, no Brasil, 57.830 casos de restrição e privação de liberdade em todo o país. O estado de São Paulo é disparadamente o que mais aplicou medidas de internação, internação provisória e semiliberdade, sendo 35.475 casos no período de 2008 a 2012.

São Paulo também aparece, de acordo com o relatório supracitado, como o estado que mais apresenta adolescentes com envolvimento no tráfico de drogas. Na maioria dos estados brasileiros, a tipificação do ato infracional revela que o roubo é a atividade mais recorrente, com uma diferença expressiva para a segunda, no caso, o tráfico. Já em São Paulo, a diferença entre essa tipificação dos casos é quase inexistente (Roubo $=3.732$; Tráfico de 
drogas $=3.7121$. Os dados indicam que o envolvimento de adolescentes no tráfico de drogas é mais preocupante nesse estado, pois, dos 5.881 casos encaminhados para medidas de internação e semiliberdade no Brasil por esse ato infracional, 3.712 são desse estado (SINASE, 2012). Esse levantamento indica a necessidade de criação de políticas públicas capazes de enfrentar essa problemática social, além de diferentes ações de mobilização social.

A educação e as práticas educativas no contexto escolar são, corriqueiramente, apontadas como mecanismos que podem romper com o envolvimento de adolescentes em atos infracionais. $\bigcirc$ grande desafio que se coloca é viabilizar o acesso à educação de qualidade para essa população, bem como garantir a permanência nesse espaço institucional. Nesse sentido, Francisco afirma que

[...] conhecer a relação entre o processo de marginalização e a educação escolar é reafirmar o compromisso entre conhecimento e contexto social, articulando teoria e prática com vistas a colaborar no processo de transformação das relações sociais (FRANCISCO, 2012, p. 36-37).

O histórico de reprovação, as defasagens de conteúdos, as expulsões e os indicadores de repetência ilustram a relação conturbada que tem sido construída entre a escola e os adolescentes com envolvimento em ato infracional (DIAS 2013; MONTEIRO, 2010). As trajetórias de insucesso desse grupo na vida acadêmica podem intensificar o sentimento de exclusão (ZHANG; WILLSON; KATSIYANNIS; BARRET; JU; JIUN-YU, 2010) e retroalimentar as condições que favorecem o não rompimento com atividades ilícitas realizadas por adolescentes, expondo-os a comportamentos classificados como contravenção penal.

Bazon, Silva e Ferrari (2013) problematizam a ideia de que a relação dos adolescentes que cometem ato infracional com a escola é sempre marcada por fracassos. Para as autoras, parte desse grupo verbaliza um período em que as experiências nessa instituição foram positivas, especialmente aqueles que conseguem manter vínculos afetivos com professores. Porém, com o passar do tempo e com a deterioração da qualidade dos relacionamentos no contexto escolar, os sentidos construídos em relação à instituição passam a ser negativos. 
O "traficante" não vai à escola: processos de escolarização de adolescentes com envolvimento no tráfico de drogas

Os estudos relacionados a essa temática investigam, majoritariamente, a relação dos professores com alunos em cumprimento de medidas socioeducativas, bem como suas concepções sobre os adolescentes (FRANCISCO; MURGO, 2015; PADOVANI; RISTUM, 2013; SILVA; SALLES, 20111 . Os sentidos atribuídos aos processos educativos pelo próprio adolescente também já foram abordados por pesquisadores da área (BAZON; SILVA; FERRARI, 2013; SANTOS; NASCIMENTO; MENEZES, 201 2). Todavia, ainda são escassos os estudos empíricos sobre a caracterização do contexto escolar na vida de adolescentes com envolvimento no tráfico.

Por se tratar de uma demanda alarmante, especialmente em algumas localidades no território nacional, faz-se necessário criar estratégias investigativas que descortinem essa realidade. Compreender as trajetórias de escolarização de adolescentes levando em consideração a tipificação do ato infracional pode revelar conteúdos ainda pouco explorados pela literatura.

Com base nessas interlocuções, o objetivo deste artigo é analisar o contexto escolar de adolescentes com histórico de envolvimento no tráfico de drogas, bem como explicitar dados sobre as experiências educacionais em escolas regulares e naquelas frequentadas durante a aplicação de medidas

194 socioeducativas.

\section{Método}

\section{Participantes e Instituições}

A pesquisa de campo foi realizada em três cidades de médio porte localizadas no interior do estado de São Paulo. Participaram desse estudo, de natureza quanti-qualitativa, 577 adolescentes e jovens, entre 12-20 anos de idade, $(M=16,01$; $D P=1,54)$, de ambos os sexos $156,3 \%$ do sexo masculino) e que recebiam atendimentos em 4 (quatro) contextos institucionais que oferecem serviços diversificados a populações infanto juvenis:

a) 2 (duas) casas de semiliberdade que atendiam adolescentes com histórico de envolvimento em atos infracionais.

b) 1 (um) Centro de Referência Especializado em Assistência Social (CREAS), responsável pela aplicação de medidas socioeducativas do tipo liberdade assistida (LA) e prestação de serviço à comunidade (PSC). 
c) Projeto social especializado no atendimento de crianças e adolescentes que estão expostos a diversos indicadores de risco (histórico de violência, extrema pobreza, trabalho infantil, entre outros).

d) Escola pública estadual localizada em uma área com índices de exclusão social.

As duas primeiras instituições atendiam adolescentes que haviam cometidos atos infracionais em diferentes tipificações. Em consonância com os objetivos deste estudo, optou-se pela seleção apenas daqueles com histórico de envolvimento no tráfico de drogas. Os instrumentos de pesquisa utilizados possibilitaram, a partir do trabalho de campo realizado na escola, a revelação de 12 casos de adolescentes com envolvimento no tráfico de drogas e que ainda não estavam sendo atendidos por nenhuma instituição especializada. Desse modo, tal como evidenciado na Figura 1, foram formados dois grupos: $\mathrm{G} 1$ = adolescentes com envolvimento no tráfico de drogas $(n=60)$ e $G 2=$ adolescentes sem histórico de envolvimento no tráfico ( $n=517)$.

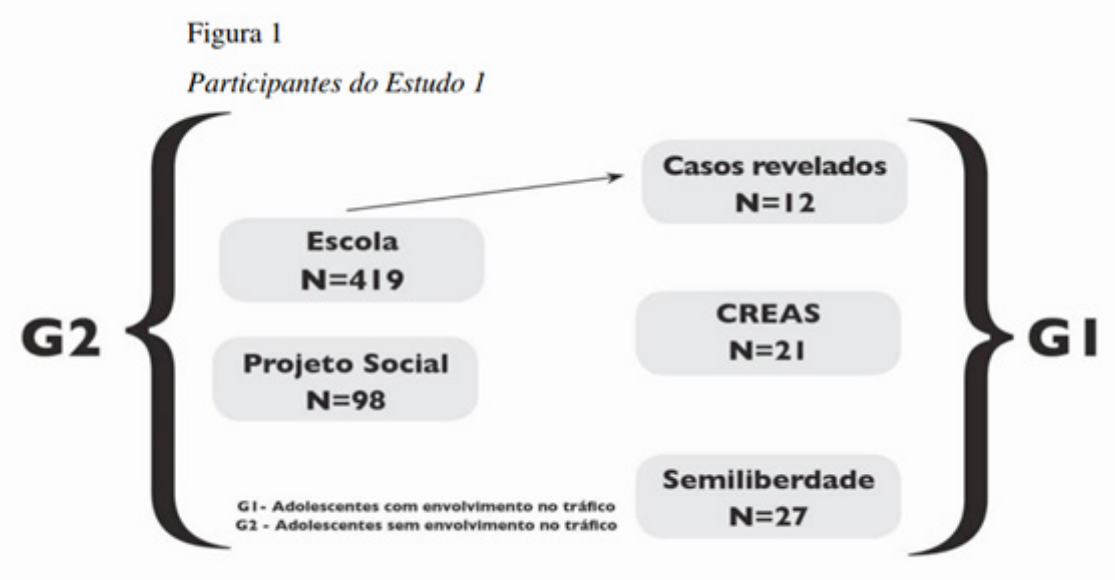

\section{Instrumentos}

Como já citado, a pesquisa se configura como de natureza quanti-qualitativa e, por isso, diferentes instrumentos de coleta dedados foram utilizados: 
"traficante" não vai à escola: processos de escolarização de adolescentes com envolvimento no tráfico de drogas

Indicadores de proteção na adolescência associados à resiliência (IPAAR): trata-se de um questionário, criado pelos autores deste artigo, que possibilita que adolescentes expressem suas percepções em relação aos serviços de atendimento e instituições disponíveis em seus contextos, de modo que é possivel averiguar a presença de indicadores de proteção que podem configurar como viabilizadores de processos de resiliência. Constam, no questionário, itens que avaliam a perspectiva dos participantes com relação ao papel dos serviços e programas voltados ao público adolescente, associados às políticas governamentais de educação, saúde, assistência social e na área jurídica, bem como aqueles oferecidos por organizações governamentais, e, ainda, as organizações família e igreja. $\bigcirc$ instrumento tem 8 (oito) seções, sendo que a primeira parte inclui aspectos sociodemográficos e as demais compostas por itens relacionados aos serviços e/ou instituições mencionados. Neste artigo, são discutidos apenas os dados relativos ao contexto escolar.

Child and Youth Resilience Measure (CYRM): Esse material foi criado a partir de uma pesquisa intercultural com 1451 adolescentes, que residiam em 14 comunidades de 11 países diferentes (UNGAR; BROWN; LIEBENBERG; OTHMAN; KWONG; ARMSTRONG, 2007), sendo validado por Ungar,

196 Liebenberg, Boothroyd, Kwong, Lee, Leblanc, Duque e Makhnach (2008) como uma medida de resiliência. $\bigcirc$ instrumento é composto por 28 itens, também estruturados no modelo da escala Likert, organizados de forma crescente, e solicita que os participantes assinalem apenas um item de acordo com seus níveis de concordância nas afirmações. $\bigcirc$ objetivo desse instrumento é identificar processos de resiliência debatidos pela literatura, levando em consideração diversos aspectos contextuais. A escolha dessa ferramenta se deu em virtude da sensibilidade de seus idealizadores para os aspectos contextuais que configuram resiliência em diferentes culturas e nacionalidades. Além disso, o instrumento possui uma seção complementar na qual os pesquisadores podem elaborar questões que incluem variáveis que estejam condizentes com os objetivos de cada pesquisa e que sejam relevantes culturalmente. Em consonância com os objetivos estabelecidos a priori na investigação, essa seção foi composta por itens relacionados ao tráfico de drogas envolvendo adolescentes e percepções valorativas dessa atividade. Esses itens foram cruciais para a definição amostral do estudo qualitativo.

Entrevistas: roteiro semiestruturado que se fundamentou na literatura específica e trouxe indicadores importantes para responder à problemática 
central, ou seja, o papel que a escola ocupa na vida de adolescentes com envolvimento no tráfico de drogas. Os participantes tinham o direito de ler as questões contidas na entrevista antes do início da técnica, negar responder parte das questões ou, até mesmo, não dar continuidade à pesquisa. Um dos pontos levantados, nessa etapa, se referia às percepções e memórias que os adolescentes tinham com relação a suas experiências escolares.

\section{Procedimentos}

Com relação ao estudo quantitativo, as aplicações dos questionários na escola e no projeto social foram realizadas em grupos que variavam de 15 (quinze) a 25 (vinte e cinco) alunos. No CREAS, os grupos eram ainda menores, sendo que, em alguns casos, os questionários foram lidos aos participantes que, em seguida, sinalizavam concordância ou não com os itens apresentados. Nas instituições de semiliberdade, as aplicações foram feitas em grupos de 3 (três) a 4 (quatro) adolescentes ou individualmente, especialmente em situações que o participante apresentava baixo repertório de escolarização. Ainda assim, cabe destacar que a maioria dos participantes, provenientes dessa instituição, não tiveram dificuldades para preencher o instrumento, demonstrando domínio e boa compreensão da língua escrita. Em média, os adolescentes levaram de 30 a 50 minutos para responder às questões dos dois instrumentos.

As entrevistas foram conduzidas, apenas, com adolescentes com histórico de envolvimento no tráfico de drogas. Por intermédio de análises estatísticas aplicadas ao segundo instrumento (CYRM), constitui-se em uma amostragem de 8 (oito) participantes. Os critérios de inclusão foram: 1) ter sido encaminhado à instituição por vinculação ao tráfico; 2) apresentar um alto score em uma das seções do CYRM, que traz elementos de valorização do tráfico de drogas. Para tanto, os valores da escala foram analisados pela técnica de análise discriminante, e um grupo, então, foi constituído; 3) Após esse procedimento de análise, o terceiro critério foi a concordância dos profissionais que atendem os adolescentes quanto à valorização do tráfico por parte desses adolescentes. Solicitou-se aos profissionais da equipe técnica da instituição de semiliberdade que levassem em consideração discursos positivos atribuídos ao tráfico que apareciam, espontaneamente, durante os atendimentos. Interessava aos pesquisadores dialogar com os adolescentes com maior envolvimento no tráfico, 
O "traficante" não vai à escola: processos de escolarização de adolescentes com envolvimento no tráfico de drogas

pois se considerava que tais participantes trariam elementos mais fundamentados e emblemáticos sobre a realidade escolar.

As entrevistas foram realizadas individualmente, em salas reservadas, num único encontro e tiveram a duração média de 50 (cinquenta) minutos. 0 material foi gravado por meio de aparelho digital e, posteriormente, transcrito na íntegra.

Ressalta-se que, durante o contato com os adolescentes, especialmente àqueles com envolvimento no tráfico, buscou-se estabelecer uma relação menos hierarquizada. Isso incluiu conversas informais antes dos procedimentos de pesquisa propriamente dito, participação nas refeições e realização de atividades dentro da instituição. Priorizou-se o valorizando as dinâmicas institucionais e os acordos estabelecidos previamente

\section{Análise dos dados}

Os dados do estudo quantitativo passaram por um processo de tabulação e, posteriormente, foram realizados testes descritivos de cada um dos

198 itens propostos nas diferentes seções dos instrumentos. $\bigcirc$ software utilizado foi o SPSS, versão 21.0. As tabelas privilegiaram análises comparativas entre adolescentes que estavam em cumprimento de medidas socioeducativas por envolvimento no tráfico $(G 1)$ e com aqueles que frequentam escolas regulares e projetos sociais (G2). Foi utilizado o teste qui-quadrado de Pearson para testar a hipótese de duas variáveis independentes, ou seja, a não significância mostra que as categorias dessas variáveis não são determinantes para a classificação dos grupos. Também foi utilizado o test $t$ de student com o propósito de verificar diferenças estatisticamente significativas entre as médias dos grupos. Já nas Tabelas que apresentavam diversas variáveis, foi aplicado o teste ANOVA para verificar o nível de significância entre os grupos, analogamente ao teste qui-quadrado.

Os dados da entrevista, que constituem o estudo qualitativo, foram submetidos à análise de conteúdo, inspirados na proposta de Bardin (201 1), e permitiram a criação de categoriais explicativas sobre o fenômeno investigado. Para aumentar o grau de confiabilidade das categorias, elas foram submetidas pelos proponentes do estudo à análise de Concordância entre Juízes, composta por uma comissão de pesquisadores experientes, com notório saber na 
temática e que não haviam participado em nenhuma etapa da pesquisa. Os níveis de concordância revelaram scores significativos para a validação dos procedimentos qualitativos.

\section{Considerações éticas}

estudo tomou como referência as normativas estabelecidas pelo Conselho Nacional de Saúde que define, pela da Portaria n 466/2012, as diretrizes para a condução de pesquisas que envolvam seres humanos. Desse modo, após a organização de toda a documentação exigida, incluindo os Termos de Consentimento Livre e Esclarecido, os Termos de Assentimento (entregues aos adolescentes), as autorizações dos dirigentes das instituições participantes, entre outros, o Comitê de Ética em pesquisa da Universidade Estadual Paulista - Campus de Presidente Prudente, emitiu parecer favorável para a realização do estudo (CAEE 26468714.0.0000.5402).

\section{Resultados}

\section{Caracterização do contexto escolar}

Como já apresentado, G1 representa o grupo de adolescentes com envolvimento no tráfico, enquanto $G 2$ representa adolescentes de uma escola pública e projeto social. Apenas um sujeito do $G 2$, vinculado ao projeto social, afirmou não frequentar nenhuma escola regular na época em que o questionário foi preenchido. Em contrapartida, no G2, 43,3\% dos adolescentes com envolvimento no tráfico não estavam matriculados em escolas. Esse dado é inquietante, tendo em vista que tanto a medida de semiliberdade quanto liberdade assistida exigiria do adolescente a frequência escolar. Pode-se inferir que alguns adolescentes estavam em descumprimento com a medida socioeducativa aplicada.

Ainda em relação à temática da evasão, 50,0\% dos participantes deixaram de frequentar a escola há menos de um ano, 26,9\% há um ano, 3,8\% dois anos e 19,2\% há mais de três anos. Entre os motivos apresentados pelos adolescentes para não frequentarem mais a escola aparece, em primeiro lugar, 
O "traficante" não vai à escola: processos de escolarização de adolescentes com envolvimento no tráfico de drogas

a justificativa de que não gostavam de ir $(51,9 \%)$, seguido de $29,6 \%$ que assinalaram outros motivos para a evasão da instituição.

Os participantes tiveram a oportunidade de avaliar a qualidade das escolas que já haviam frequentado. Mesmo os adolescentes que não estavam frequentando uma escola na época em que a pesquisa de campo foi realizada puderam responder a essa questão. Nesse caso, foi solicitado que se lembrassem do período que costumavam ir, evocando os sentimentos e ideias relativos àquele período (Tabela 1). A maioria dos participantes do $G 1$ indicou que a qualidade da escola é regular (45\%), seguido por 36,7\% que afirmam que as escolas são boas e 9,0\% que apontam as escolas como muito boas. Já para $G 2$, a maior parte informou que consideram suas escolas boas $(45,6 \%)$, 41,0 disseram que são regulares e 6,3\% muito boas. Os dados mostram semeIhança na maneira com que os dois grupos avaliam a qualidade das escolas que frequentaram, de modo que não foram encontradas variações estatísticas significativas. Somando-se, por exemplo, as alternativas "boa" e "muito boa", encontra-se a proporção de $51,7 \%$ para $G 1$, e $51,9 \%$ para $G 2$.

\section{Tabela 1}

\section{Avaliação da qualidade da escola}

\begin{tabular}{lcc} 
Avaliação da qualidade da escola & $\mathrm{G} 1$ & $\mathrm{G} 2$ \\
\cline { 2 - 2 } & $\mathrm{n}(\%)$ & $\mathrm{n}(\%)$ \\
Muito ruim & $1(1,7)$ & $11(2,4)$ \\
Ruim & $1(1,7)$ & $21(4,6)$ \\
Razoável & $27(45,0)$ & $188(41,0)$ \\
Boa & $22(36,7)$ & $209(45,6)$ \\
Muito boa & $9(15,0)$ & $29(6,3)$ \\
*Nota | p $<0,05$ (ANOVA) & &
\end{tabular}

Foi elaborada a Tabela 2 para apresentação dos dados alusivos ao histórico de reprovação no contexto escolar para os dois grupos. Para G1, apenas $21,7 \%$ afirmam nunca ter reprovado uma série, enquanto, para G2, esse número sobe para 85,5\%, evidenciando uma diferença significativa entre as duas populações analisadas. Além disso, 66,7\% dos participantes do G1 
afirmam que já reprovaram de 1 a 3 vezes, enquanto, para $G 2$, esse número cai para $14,5 \%$. Os dados ainda mostram que $6,7 \%$ dos adolescentes $(n=$ 3) que constituíram o $G 1$ já reprovaram 5 ou 6 vezes durante a trajetória de escolarização.

\section{Tabela 2 \\ Histórico de reprovação}

Já repetiu alguma série

\begin{tabular}{lcc} 
& $n(\%)$ & $n(\%)$ \\
Não & $13(21,7)$ & $396(85,5)^{\star}$ \\
\hline Sim & $47(78,3)^{\star}$ & $67(14,5)$ \\
\hline \multicolumn{1}{c}{ Quantas vezes já reprovou } & $\mathrm{G} 1$ & $\mathrm{G} 2$ \\
& $\mathrm{n}(\%)$ & $\mathrm{n}(\%)$ \\
Uma & $16(26,7)$ & $54(11,5)$ \\
Duas & $11(18,3)$ & $8(1,7)$ \\
Três & $13(21,7)$ & $6(1,3)$ \\
Quatro & $2(3,3)$ & $1(0,2)$ \\
Cinco & $1(1,7)$ & $0(0)$ \\
Seis & $3(5,0)$ & $0(0)$
\end{tabular}

*Nota | p-valor = 0,05 (qui-quadrado)

A Tabela 3 traz dados que podem ser associados a questões de indisciplina, comportamentos tidos como inapropriados para a instituição escolar ou ainda com dificuldades de adaptação dos adolescentes nesse contexto. $16,7 \%$ dos participantes de G 1 informaram que já foram expulsos da escola, enquanto 2,2\% de G2 trouxeram a mesma informação. Similarmente, 16,6\% do Gl apontam que já foram expulsos uma ou duas vezes dessa instituição, sendo que essa informação cai para 1,5 para G2. Apenas 10,0\% do G1 afirmaram nunca ter levado suspensão nas escolas, contrastando com 73,6\% do G2. As diferenças continuam quando analisada a quantidade de vezes em que os participantes informaram ter sido suspensos, uma vez que $51,6 \%$ do G1 indicam que já foram suspensos entre duas e quatro vezes, contra $21,7 \%$ do G2. A última linha da Tabela revela, ainda, que 38,3\% dos respondentes 
"traficante" não vai à escola: processos de escolarização de adolescentes com envolvimento no tráfico de drogas

do $G 1$ já receberam cinco ou mais vezes suspensão na escola, sendo que esse valor é de $\mathrm{G} 2$ 4,8\% para $\mathrm{G} 2$.

\section{Tabela 3}

Histórico de expulsões e suspensões na escola

Já foi expulso da escola

Não

Sim

Quantas vezes foi expulso

Nenhuma

Uma

Duas

Quantas vezes levou suspensão**

202

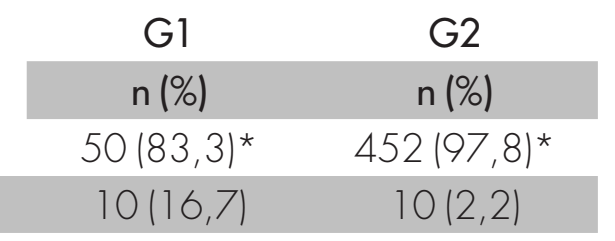

G1

G2

$\begin{array}{cc}\mathrm{n}(\%) & \mathrm{n}(\%) \\ 50(83,3)^{* *} & 464(98,5)^{* *} \\ 8(13,3) & 6(1,3)\end{array}$

$2(3,3) \quad 1(0,2)$

$\begin{array}{cc}\mathrm{G} 1 & \mathrm{G} 2 \\ \mathrm{n}(\%) & \mathrm{n}(\%) \\ 6(10,0) & 340(73,6) \\ 14(23,3) & 64(13,9) \\ 17(28,3) & 36(7,8) \\ 23(38,3) & 22(4,8)\end{array}$

Cinco vezes ou mais

* Nota | p-valor = 0,05 (qui-quadrado)

$*$ *Nota $\mid$ p-valor $=0,05$ (ANOVA)

A Tabela 4 apresenta afirmações positivas em relação à escola, sendo que os adolescentes participantes podiam assinalar o nível de concordância com cada uma das sentenças. É importante esclarecer que cada um dos itens possuía, na estrutura original do instrumento, possibilidades de respostas escalonadas de 1 a 5 (modelo likert), sendo que, quanto maior o número assinalado pelo sujeito, maior nível de concordância era constatado, indicando, dessa maneira, que a escola ocupa um espaço positivo na vida dos participantes.

Para apresentação das Tabelas, procedeu-se com o agrupamento das respostas 1 e 2 ("Discordo totalmente" e "Discordo") e 4 e 5 ("Concordo" e "Concordo Totalmente"). $\bigcirc$ primeiro aspecto que chama atenção foi a 
diferença encontrada no primeiro item ("Eu me sinto feliz quando estou na escola"). Para o G1, 20,0\% dos participantes apontaram que discordam dessa afirmação, enquanto apenas $6,4 \%$ do $G 2$ apresentaram discordância da sentença. Esses valores estão aproximados do item "A escola é um lugar onde aprendo coisas importantes", que mostra que 20\% de Gl discordam e 8,2\% para o G2. Como esses itens do questionário apontam para questões da avaliação positiva das instituições levando em consideração aspectos subjetivos, pode-se afirmar que a escola ocupa um espaço menos protetivo na percepção de adolescentes com histórico de envolvimento no tráfico de drogas.

Sobre os relacionamentos estabelecidos na escola, tem-se que as relações entre pares são menos valorizadas para $G 1$ do que para $G 2$, uma vez que $53,3 \%$ dizem que gostam de ir para escola porque têm a oportunidade de encontrar amigos, enquanto, para $G 2$, esse número passa para $74,4 \%$. Em contrapartida, existe uma relação mais polarizada sobre os professores no G1, uma vez que 35,0\% discordam que podem confiar com seus professores quando têm problemas, enquanto para $\mathrm{G} 2$ esse número cai para 26,0\%. Percebe-se, ainda, que uma proporção maior dos participantes de $G 1$ apresentaram níveis de confiança nos professores ( $G 1=45,0 \%$; $G 2=32,2 \%$ ).

É importante frisar que não havia a diferenciação para os grupos entre as escolas regulares e àquelas frequentadas quando cumpriam medida socioeducativa, o que talvez possa explicar as diferenças numéricas. Como observado, os relacionamentos com educadores que atuam em unidades de medida socioeducativa são avaliadas positivamente pelo G1. Essas discussões são retomadas na apresentação do estudo qualitativo.

A relação entre escola e comunidade também foi mais bem avaliada por $G 1$ em relação aos índices apontados por G2. No item que apresenta a afirmativa de que as pessoas na comunidade participam de atividades que são propostas na escola, portanto indicam maior interação entre esses dois contextos, tem-se que 27, $1 \%$ do G 1 concordam, contra 1 1, 1\% do G2. Ainda assim, para os dois grupos, esses números são baixos e revelam a falta de diálogo entre o contexto escolar e comunitário, tão recorrentemente apontados na literatura como os principais espaços de desenvolvimento de crianças e adolescentes.

Os três últimos itens apresentados na Tabela são alusivos às representações que perpassam o imaginário dos grupos com relação à importância 
O "traficante" não vai à escola: processos de escolarização de adolescentes com envolvimento no tráfico de drogas

da escola. As respostas foram, provavelmente, embasadas na incorporação de discursos e representações sociais que atribuem valores à escolarização. Os resultados entre G1 e G2 são similares a ponto de não apresentarem diferenças estatísticas significativas de acordo com o test t. Contudo, uma diferença entre os grupos apareceu no último item ("Pessoas que vão à escola têm posições importantes na sociedade"), uma vez que 78,3\% do G1 dizem que concordam e $64,3 \%$ de G2. Esses dados chamam a atenção, especialmente porque indicam que o Gl parece reconhecer mais a importância da escolarização em sua cultura, embora tenha mais dificuldades de permanência e índices satisfatórios nesse contexto, tal como constatado nessa investigação. Como boa parte dos participantes de Gl não frequentam escolas, isso pode revelar uma expectativa negativa com relação ao próprio futuro.

\section{Tabela 4}

\section{Indicadores de Proteção associados à escola}

G1

$\begin{array}{cccccc}\begin{array}{c}\text { Discordo } \\ \mathrm{n}(\%)\end{array} & \begin{array}{c}\text { Mais ou } \\ \text { menos }\end{array} & \begin{array}{c}\text { Concordo } \\ \mathrm{n}(\%)\end{array} & \begin{array}{c}\text { Discordo } \\ \mathrm{n}(\%)\end{array} & \begin{array}{c}\text { Mais ou } \\ \text { menos } \\ \mathrm{n}(\%)\end{array} & \begin{array}{c}\text { Concordo } \\ \mathrm{n}(\%)\end{array} \\ & \mathrm{n} & & \end{array}$

A. Eu me sinto feliz na escola*

B. A escola é um lugar onde aprendo coisas importantes

$12(20,0) \quad 31(51,7) \quad 17(28,3) \quad 30(6,4) \quad 281(59,9) \quad 158(33,7)$

$1(1,7) \quad 6(10,2) \quad 52(88,1) \quad 3(0,6) \quad 52(11,1) \quad 413(88,2)$

C. Eu me sinto capaz de resolver a maioria das atividades da escola*

$12(20,0) \quad 25(41,7) \quad 23(38,3) \quad 38(8,2) \quad 201(43,4) \quad 224(48,4)$

D. Gosto de ir à escola para ver meus amigos*

$11(18,3) \quad 17(28,3) \quad 32(53,3) \quad 24(5,1) \quad 96(20,5) \quad 348(74,4)$

E. Eu posso confiar nos meus professores quando tenho problemas

F. As pessoas que trabalham na escola me tratam com respeito

$21(35,0)$

$12(20,0)$

$27(45,0)$

$121(26,0)$

$199(42,8) \quad 145(31,2)$

$9(15,3)$

$13(22,0)$

$37(62,7)$

$47(10,0)$

$150(32,1) \quad 271(57,9)$

G. As pessoas no meu bairro acreditam que é importante frequentar a escola

$4(6,9) \quad 8(13,8) \quad 46(79,3) \quad 30(6,5) \quad 94(20,3) \quad 340(73,3)$

H. Pessoas no meu bairro participam de eventos da escola*
$16(17,1) \quad 27(45,8) \quad 16(27,1) \quad 193(41,3) \quad 222(47,5) \quad 52(11,1)$ 
Gl

\begin{tabular}{lcccccc}
\multicolumn{1}{c}{ Falando sobre escola } & $\begin{array}{c}\text { Discordo } \\
\mathrm{n}(\%)\end{array}$ & $\begin{array}{c}\text { Mais ou } \\
\text { menos } \\
\mathrm{n}(\%)\end{array}$ & $\begin{array}{c}\text { Concordo } \\
\mathrm{n}(\%)\end{array}$ & $\begin{array}{c}\text { Discordo } \\
\mathrm{n}(\%)\end{array}$ & $\begin{array}{c}\text { Mais ou } \\
\text { menos } \\
\mathrm{n}(\%)\end{array}$ & $\begin{array}{c}\text { Concordo } \\
\mathrm{n}(\%)\end{array}$ \\
$\begin{array}{l}\text { I. Pessoas do meu bairro } \\
\text { ajudam a tomar decisões para } \\
\text { a escola }\end{array}$ & $31(53,4)$ & $14(24,1)$ & $13(22,4)$ & $281(60,2)$ & $147(31,5)$ & $39(8,4)$ \\
$\begin{array}{l}\text { J. Escola é um lugar que todo } \\
\text { mundo devia frequentar }\end{array}$ & $4(6,7)$ & $6(10,0)$ & $50(83,3)$ & $12(2,6)$ & $32(6,9)$ & $420(90,5)$ \\
$\begin{array}{l}\text { K. Escola ajuda as pessoas a } \\
\text { realizar os objetivos na vida }\end{array}$ & $5(8,3)$ & $5(8,3)$ & $50(83,3)$ & $11(2,4)$ & $51(10,9)$ & $405(86,7)$ \\
$\begin{array}{l}\text { L. Pessoas que vão à escola } \\
\text { têm posições importantes na } \\
\text { sociedade }\end{array}$ & $6(10,0)$ & $7(11,7)$ & $47(78,3)$ & $34(7,3)$ & $133(28,4)$ & $301(54,3)$ \\
*Nota | p-valor = $=0,05$ (Test $\dagger)$ & & & & &
\end{tabular}

\section{Relatos paradoxais sobre as trajetórias de escolarização}

Os resultados aqui discutidos baseiam-se em trechos das entrevistas conduzidas e versam sobre as experiências subjetivas dos adolescentes em relação aos contextos escolares que conheceram antes e depois do período de aplicação de medida socioeducativa. Desse modo, foi possível elaborar análises sobre as práticas educativas formais que os participantes estiveram engajados no período de internação ou quando estavam cumprindo o regime de semiliberdade.

Os adolescentes, com exceção de Marcelo, descrevem as possibilidades e oportunidades que os processos de escolarização podem trazer. Reconhecem que, dificilmente, as pessoas são bem sucedidas se não adquirirem formações acadêmicas consideradas socialmente como satisfatórias. Narram poucas experiências positivas no contexto escolar, limitando-se a lembranças com alguns professores, funcionários, amigos e, em menor frequência, com o próprio processo de aprendizagem.

Além disso, relatos de violência e agressão também foram encontrados, principalmente com diretores e professores. Os participantes mostram que se sentiam desconfortáveis no contexto escolar e, de certa forma, inadaptados às rotinas propostas. Talvez por esse aspecto a escola tenha sido apontada como uma instituição positiva para o futuro, mas com poucos referenciais 
O "traficante" não vai à escola: processos de escolarização de adolescentes com envolvimento no tráfico de drogas

positivos relacionados ao presente ou capaz de gerar o senso de pertencimento à instituição.

Pesquisador: E como era a sua relação com os seus professores?

Bernardo: Eu não tratava bem eles [...] eu não sei direito, mas eu acho que era a revolta de ter que ir pra escola, porque ninguém gosta, eu não sei explicar direito. Mas acho que era mais a revolta de estar lá, ter que estudar (BERNARDO, 2015).

Pesquisador: Você gosta de ir pra escola?

Marcelo: Não.

Pesquisador: $\bigcirc$ que você mais detesta na escola?

Marcelo: Tudo, não gosto de nada na escola.

Pesquisador: Mas como você faz, porque aqui você é meio que obrigado a ir (no regime de semiliberdade)?

Marcelo: Eu vou, tenho que ir, marcar presença. Eu fico lá conversando, escutando música no celular.

Pesquisador: Você acha que os estudos são importantes na sua vida?

Marcelo: Eu acho que não.

Pesquisador: E como você acha que vai ser pra você?

Marcelo: Com estudo ou sem estudo acho que tanto faz (MARCELO, 2015).

Os participantes falaram das dificuldades em permanecer na escola, especialmente após o envolvimento no tráfico. $\bigcirc$ abandono escolar é concomitante a esse momento em quase todos os casos. Alguns dos participantes afirmaram que, no início, conseguiam conciliar o tráfico e a escola, mas que, com o aumento das demandas, necessitavam se ausentar cada vez mais para executar a comercialização das substâncias psicoativas. Assim como ocorreu com os familiares, os funcionários da escola não notaram o início dessas atividades. De acordo com os relatos de alguns dos participantes, a equipe pedagógica, apenas, observava a ausência constante dos adolescentes nas aulas.

Pesquisador: E a escola? Você curtia? 
Gustavo: Eu ia só de vez em quando [...] antes eu ia todo dia, não faltava. Depois que eu comecei a vender (drogas) eu ia só de vez em quando. Ai eu dava um jeito de não ir. Eu fiquei 4 meses sem ir pra escola. Sem ir nem um dia.

Pesquisador: Ninguém percebeu?

Gustavo: Ah, eles ligavam, só que eu enganava minha mãe, falava que eles estavam mentindo pra ela. Ai ela ficava meio assim, ai não sei (GUSTAVO, 2015).

Os adolescentes, durante as entrevistas, apresentaram claramente as diferenças entre as trajetórias escolares em escolas regulares e as experiências que tiveram nos espaços educativos dentro da instituição onde cumpriram medida socioeducativa em regime fechado. Valorizaram as relações interpessoais estabelecidas com os educadores dessas instituições /onde cumpriam medidas socioeducativas). Afirmam que os educadores e demais profissionais são pessoas acessíveis e que compreendiam suas dificuldades. Mostraram-se satisfeitos com a possibilidade de participar de diferentes projetos extracurriculares, como, por exemplo, concursos que abrangiam as diferentes unidades de internação. Alguns dos participantes afirmam que só aprenderam a ler e escrever enquanto cumpriam a medida socioeducativa.

Pesquisador: E a escola pra você?

Artur: Ah, antes eu não gostava, agora eu gosto. Porque antes eu só ia pra bagunçar, agora eu estou querendo terminar meus estudos logo pra arrumar um serviço, tirar carta.

Pesquisador: Você tem dificuldade com as matérias na escola?

Artur: Não. Em matemática eu ganhei em segundo lugar num projeto estadual da " $X$ " (instituição que o adolescente cumpriu medida socioeducativa em regime fechado). Em primeiro foi " $X$ " (nome da cidade) e em segundo eu. A senhora (educadora da instituição) falou que era pra eu ter ganhado em 100 pontos, mas ficou sem internet na " $X$ " (nome da instituição). Era pra eu ter ganhado um notebook.

Pesquisador: E você tem boas notas?

Artur: Tenho, só 10 mesmo. Na "X" (instituição) eu era o único que tirava 10 em geografia, porque eu me empenhava (ARTUR, 2015).

Pesquisador: E hoje os estudos têm algum sentido pra você? 
O "traficante" não vai à escola: processos de escolarização de adolescentes com envolvimento no tráfico de drogas

Thiago: Tem, é uma chave de muitas portas para a vida, é muita coisa boa, só produtividade. Porque sem estudo você não arruma nada. Até bandido precisa de inteligência. Se for um bandido burro o povo passa pra trás. Tem que ser um cara inteligente, porque pra estar no crime tem que ter suas malandragens e suas inteligências. Então na escola aprende tanto pra usar dentro da escola como lá fora. E a escola que eu aprendi mesmo foi na " $X$ " (instituição que o adolescente cumpriu medida socioeducativa em regime fechado) (THIAGO, 2015).

\section{Discussão}

É preocupante o índice de evasão escolar encontrado nos adolescentes que tiveram envolvimento no tráfico. Além disso, o motivo que mais colaborou para esse fato, de acordo com as respostas dos participantes, foi que eles não gostavam de ir à escola. $\bigcirc$ histórico de reprovações, nesse grupo, também deve ser levado em consideração quando se buscam explicações para o abandono escolar.

A inadequação dos currículos escolares às realidades juvenis, os conteúdos que são apresentados através de metodologias tradicionais, as estruturas físicas precárias dos prédios, o baixo repertório cultural proveniente da inacessibilidade a equipamentos sociais disponíveis, dificuldades materiais das famílias para garantir a permanência, entre tantos outros aspectos, podem colaborar nos processos de evasão escolar na adolescência de modo geral IGOMES; SOUZA, 2009; DESTRO; SOUZA, 2012; SANTOS; NASCIMENTO; MENEZES, 2012). No caso dos adolescentes em conflito com a lei, tal como apresentado por Monteiro (2010), Dias (2011) e Lourenção (2015), existe, ainda, uma dissociação entre os objetivos estabelecidos pelas instituições escolares e os interesses dos adolescentes, de modo que atividades em outros espaços e com outras características se mostram mais atrativas para esse grupo.

Com base no material empírico levantado, pode-se afirmar que o não alinhamento entre as expectativas traçadas pela instituição escolar e a realidade de adolescentes com envolvimento no tráfico repercute na produção da indisciplina e, consequentemente, no acúmulo de um histórico de suspensões e expulsões que intensificam estigmas de "desajustados" que esses adolescentes recebem em diversos espaços sociais. Com isso, a arbitrariedade de mantê-los 
nas escolas, diante das conjunturas expostas, implica, muitas vezes, o acarretamento de outros problemas, tendo em vista que conflitos sociais, como o caso da indisciplina, têm se transformado problemáticas judiciais (ver o trabalho de AVILA, 2015). Argumenta-se que as condutas de adolescentes em conflito com a lei nas escolas também devam ser analisadas com base nas expectativas dos próprios alunos, mesmo que isso signifique que suas vozes ecoarão como denúncia a um modelo institucional considerado retrógado.

Apesar dessa constatação, a pesquisa revelou que existe um processo de valorização da escola, uma vez que os participantes reconhecem que aprendem coisas importantes para o futuro. Mas é essencial levar em consideração as representações sociais que esses grupos incorporam, advindos de práticas discursivas que prescrevem fortemente sucesso e ascensão social para os indivíduos que atingem níveis de escolarização satisfatórios. $\bigcirc$ fato de boa parte dos participantes afirmarem que não se sentem felizes quando estão na escola é um exemplo emblemático que revela esses paradoxos.

Os relacionamentos interpessoais no contexto escolar também não foram bem avaliados, sendo o relacionamento com os professores o mais conturbado. As más condições de trabalho do professor, o baixo repertório cultural e as estratégias tradicionais de ensino corroboram a construção de relacionamentos interpessoais esvaziados de sentidos (CAMARGO; GUTN; MOTTA; ZANANDREA; FABRI, 2012), ocasionando a homogeinização das necessidades dos alunos e a diminuição de significados positivos que as escolas podem adquirir na vida de professores e alunos (FISS; BARROS, 2014; LÓ, 2010).

As trajetórias de vida dos adolescentes do tráfico requerem dos professores e dos profissionais que atuam na escola o estabelecimento de relações afetivas, virtuosas e que respeitem as demandas desses alunos. As condições objetivas do contexto educacional brasileiro não favorecem tais princípios. Daí a necessidade de articulação da sociedade como um todo em busca de estratégias de valorização e melhorias da qualidade da educação pública. Só assim haverá um salto qualitativo nas relações interpessoais no contexto escolar, reverberando, também, na qualidade dos serviços educacionais, prestados a adolescentes em cumprimento de medidas socioeducativas.

Os dados ainda mostram que a relação entre escola e comunidade é enfraquecida. Muito se tem debatido sobre o potencial que existe na articulação desses dois contextos. Alves e Varela (2012) propõem a substituição 
O "traficante" não vai à escola: processos de escolarização de adolescentes com envolvimento no tráfico de drogas

de expressões como "escola aberta" [à comunidade] por "escola em parceria" [com a comunidade], pois alertam para a necessidade da "passagem da lógica burocrática baseada no cumprimento dos normativos para uma lógica de parceria baseada na negociação entre atores sociais" (p. 37), em prol da resolução efetiva de questões sociais que surgem e que remetem, necessariamente, a esses dois contextos.

Diversos estudos foram realizados no Brasil recentemente com foco no encaminhamento de projetos que articulem, sistematicamente, ações entre as escolas e os contextos comunitários (PARENTE, 2012; SILVA, 2012; CARNEIRO, 2011 ; GANZ, 201 1). Esses trabalhos apontam para a necessidade de as escolas estarem próximas às comunidades do ponto de vista geográfico (UNGAR; LIEBENBERG; DUDDING; ARMSTRONG; VIJVER, 20131, mostram a relevância da utilização de metodologias participativas que revelem as demandas locais e promovam um nivelamento das expectativas educacionais, bem como destacam a necessidade de conhecer os sentidos das práticas educativas na vida dos adolescentes. $O$ trabalho coletivo e articulado entre comunidade e escola pode se consolidar com uma ferramenta pujante para a diminuição dos indicadores de vulnerabilidade que assolam adolescentes, incluindo grupos que 210 tiveram envolvimento no tráfico ou que estão expostos a essa possibilidade.

Os baixos índices de escolarização e a dificuldade de adaptação no contexto escolar também podem configurar fatores significativos para que haja reincidência no tráfico. Com base nas pesquisas de Silva e Salles (2011), Bazon, Silva e Ferrari (2013) e Padovani e Ristum (2013), aponta-se a necessidade de discussões de caráter pedagógico que possam estabelecer ações educativas mais alinhadas com as expectativas de adolescentes com histórico de envolvimento no tráfico de drogas, visibilizando participação social e, por conseguinte, a não reincidência no ato infracional.

A pesquisa mostrou uma correlação entre o início do tráfico e a evasão escolar. Além disso, as relações na instituição se mostram complexas, com relatos de desrespeito mútuo entre os adolescentes e educadores e com indicadores de violência alarmantes. Os índices de reprovação também devem ser levados em consideração, pois estão relacionados com a evasão escolar (CASTELAR; MONTEIRO; LAVOR, 2013), especialmente no caso dos adolescentes do tráfico, que acabam ocupando seu tempo com outras atividades. 
Os participantes argumentam que a escola é importante na vida das pessoas e que podem trazer coisas boas para o futuro, mas, ao mesmo tempo, não conseguem permanecer na instituição e dizem que não gostam das atividades que são propostas. Ao que parece, existe uma incorporação dos discursos da cultura ocidental que valoriza os processos de escolarização formal (UNGAR, 2007), mas não existe, efetivamente, um engajamento dos jovens. Os sentidos que as atividades escolares /sobre essa temática ver ASBAHR; SOUZA, 2014) adquirem na vida dos adolescentes com envolvimento no tráfico de drogas serão determinantes para garantir sua permanência ou evasão.

Além disso, foi intrigante encontrar, nos discursos dos adolescentes, a preferência pelas escolas oferecidas dentro das instituições onde eles cumpriram medidas socioeducativas em regime fechado, em detrimento das escolas regulares que haviam frequentado. Boa parte do grupo entrevistado afirmou que só aprendeu a ler e escrever enquanto cumpria a medida. Esses dados trazem alguns elementos para debate: 1) isso significa que existe a potencialidade de aprendizagem de conteúdos acadêmicos nesses adolescentes, o que contraria retóricas conservadoras apresentadas por algumas áreas do conhecimento; 2) a qualidade das relações interpessoais com os profissionais que atuam nas escolas dentro da instituição de medidas socioeducativa mostrou-se capaz de alterar também a relação do aluno com o processo de aprendizagem; 3) o fato de os professores reconhecerem as especificidades e as dificuldades dos alunos que tiveram envolvimento no tráfico, não só em termos da apropriação do conteúdo, mas também em relação aos contextos históricos e sociais, configurou uma estratégia eficiente para a construção de novos sentidos e significados para a escolarização.

\section{Considerações finais}

trabalho evidenciou as trajetórias escolares de adolescentes com histórico de envolvimento no tráfico em escolas regulares, notoriamente marcadas por fracassos, desencontros e falta de sentidos. Também foram identificados aspectos positivos em relação às ações educativas, organizadas no interior das instituições de medidas socioeducativas, o que abre margem para novas questões investigativas. A utilização de uma abordagem quanti-qualitativa, no 
O "traficante" não vai à escola: processos de escolarização de adolescentes com envolvimento no tráfico de drogas

trabalho de campo, viabilizou o surgimento de aspectos negligenciados pela literatura da área e evidenciou a potencialidade na utilização de instrumentos com diferentes estruturas na pesquisa com adolescentes.

Faz-se necessário, todavia, destacar as limitações do estudo e as novas questões investigativas que surgiram através do trabalho de campo. Os participantes responderam aos questionários e participaram das entrevistas enquanto ainda recebiam atendimentos nas instituições de medidas socioeducativas. Considera-se que os discursos apresentados podem estar influenciados por práticas institucionais que visam ao controle social. Outros desenhos metodológicos podem captar com mais profundidade os significados da escolarização, especialmente estudos com recortes longitudinais, de história oral ou que proponham a triangulação de dados a partir de diferentes fontes de pesquisa.

Ademais, se torna relevante analisar, com profundidade, as práticas educativas valorizadas pelos adolescentes nas instituições de medidas socioeducativas, especialmente em relação aos educadores, apontados como referências significativas na vida dos participantes. Caracterizar essas relações e mapear os processos de formação docente e as concepções de adolescên-

212 cia desses profissionais podem auxiliar na compreensão de práticas exitosas e na consolidação de ações educativas mais condizentes com as necessidades e interesses dos adolescentes.

Espera-se que os dados apresentados, no decorrer do manuscrito, possam subsidiar debates sobre a relação entre escola e adolescência em conflito com a lei. É de conhecimento da comunidade científica os desafios postos aos profissionais da educação em lidar com essas demandas. Levar em consideração as especificidades do ato infracional, como proposto nessa análise das trajetórias de escolarização de adolescentes com envolvimento no tráfico de drogas, pode descortinar elementos ainda obscurecidos na literatura.

\section{Referências}

ALLEN, Andrea; LO, Celia. Drugs, guns, and disadvantaged youths. Crime \& Delinquency, New York, v. 58, n. 6, p. 932-953, nov. 2012.

ALVES, Mariana Gaio; VARELA, Teresa. Construir a relação escola-comunidade educativa: uma abordagem exploratória no conselho de Almada. Revista Portuguesa de Educação, Braga, v. 25, n. 2, p. 31-61, 2012. 
ARTUR. Entrevista. (B, letra inicial da cidade). São Paulo, 27 jan. 2015.

ASBAHR, Flávia Silva Ferreira; SOUZA, Marilene Proença Rebello de. "Por que aprender isso, professora?" Sentido pessoal e atividade de estudo na psicologia histórico-cultural. Estudos de Psicologia, Natal, v. 19, p. 169-178, jul./set. 2014.

AVILA, Lisélen de Freitas. Socioeducação e violências nas escolas: as medidas socioeducativas em meio aberto e a interface com a judicialização das violências nas escolas. Saarbrücken: Novas Edições Acadêmicas, 2015.

BARDIN, Laurence. Análise de conteúdo. Tradução Luís Antero Reto e Augusto Pinheiro. 4. ed. Lisboa: Edições 70, 2011.

BAZON, Mariana Rezende; SILVA, Jorge Luis da; FERRARI, Renata Martins. Trajetórias escolares de adolescentes em conflito com a lei. Educação em Revista, Belo Horizonte, v. 29, n. 2, p. 175-199, jun. 2013.

BERNARDO. Entrevista. (M, letra inicial da cidade). São Paulo, 14 jan. 2015.

BRASIL. Sistema Nacional de Medidas Socioeducativas (SINASE). Lei n 12.594, de 18 de janeiro de 2012. Disponível em: http://www.planalto.gov.br/ccivil_03/_ato20112014/2012/lei/l12594.htm. Acesso em: 29 fev. 2016.

CAMARGO, Maria Emília; GUTN, Sérgio Cavagnoli; MOTTA, Marta Elizete Ventura da; ZANANDREA, Gabriela; FABRI, Jonas Pedro. As abordagens educacionais nas relações professor-aluno e seus reflexos na gestão organizacional. Revista Gestão, Inovação e Tecnologia, São Cristóvão (Sergipe), v. 2, n. 1, p. 52-63, jan./mar. 2012.

CARNEIRO, Suzana Filizola Braziliense. A articulação entre escola e comunidade do entorno em um projeto de literatura marginal: um olhar fenomenológico. 2011 . 280f. Dissertação (Mestrado em Educação Psicologia da Educação)- Pontifica Universidade Católica de São Paulo, São Paulo, 2011.

CASTELAR, Pablo Urano de Carvalho; MONTEIRO, Vitor Borges; LAVOR, Daniel Campos. Um estudo sobre as causas do abandono escolar nas escolas públicas de ensino médio no estado do Ceará. In: BARRETO, Flávio Ataliba Flexa Daltro; MENEZES, Adriano Sarquis de; DANTAS. Régis Façanha; ALBUQUERQUE, Emanuel Lindembreg Silva; SOUSA, Fátima Juvenal de. (Org.). Economia do Ceará em Debate. Fortaleza: Ipece, 2013.

DESTRO, Carla Maria Ariano; SOUZA, Luiz Augusto de Paula. Linguagem oral e escrita em adolescentes infratores institucionalizados. Revista CEFAC, São Paulo, v. 14, n. 6, p. 10201027, ago. 2012. 
O "traficante" não vai à escola: processos de escolarização de adolescentes com envolvimento no tráfico de drogas

DIAS, Aline Fávaro. O jovem autor de ato infracional e a educação escolar: significados, desafios e caminhos para a permanência na escola. 2011. 100f. Dissertação (Mestrado em Educação) - Programa de Pós Graduação em Educação, Universidade Federal de São Carlos, 2011.

Entre sociabilidade e movimentos de resistência: o significado da educação escolar para jovens autores de ato infracional. Revista Eletrônica de Educação, São Carlos, v. 7, n. 1, p. 70-87, maio. 2013.

DOWDNEY, Luke. Crianças do tráfico - um estudo de caso de crianças em violência armada organizada no Rio de Janeiro. Rio de Janeiro: 7 Letras, 2004.

FARIA, Ana Amélia Cypreste; BARROS, Vanessa de Andrade. Tráfico de drogas: uma opção entre escolhas escassas. Psicologia e Sociedade, Florianópolis, v. 23, n. 3, p. 536-544, set./dez. 2011.

GANZ, Sibele Terezinha Carvalho. Integração da escola com a comunidade na perspectiva de desenvolvimento local: um estudo comparativo entre duas escolas estaduais do Paraná. 2011 . 224f. Dissertação (Mestrado em Gestão Urbana) - Pontifícia Universidade Católica do Paraná, Curitiba, 2011.

214 GUSTAVO. Entrevista. (M, letra inicial da cidade). São Paulo, 17 jan. 2015.

FEFFERMANN, Marisa. Vidas arriscadas. Petrópolis: Vozes, 2006.

FRANCISCO, Júlio Cesar. Educação escolar e marginalização de adolescentes autores de atos infracionais. Revista UNISAL, Americana, n. 26, p. 35-54, jan./jun. 2012.

FRANCISCO, Marcos Vinicius; MURGO, C. S. O papel da escola na trajetória de adolescentes autores de atos infracionais: concepções de professores. Nuances, Presidente Prudente, v. 26, n. 1, p. 98-120, jan./abr. 2015.

FLOYD, Leah; ALEXANDRE, Pierre; HEDDEN, Sarra Hedden; LAWSON, April; LATIMER, Wiallian; GILES, Nathaniel. Adolescent drug dealing and race/ethnicity: a population-based study of the differential impact of substance use on involvement in drug trade. The American Journal of Drug and Alcohol Abuse, Ann Arbor, v. 36, n. 2, p. 87-91, mar. 2010.

GOMES, Cláudia; SOUZA, Vera Lúcia Trevisan. Fracassos, representações e exclusões no processo de permanência na escola. Revista Psicopedagogia, São Paulo, v. 26, n. 79, p. $41-47,2009$. 
GUITART, Moisés Esteban. The consumer capitalist society and its effects on identity: a macro cultural approach. Revista Psicologia Política, São Paulo, v. 1 1, n. 21 , p. 159-170, jun. 2011.

LÓ, Judithe Eva Duppont. Uma escola para todos e para cada um: escola inclusiva, uma comunidade de aprendizes. Conjectura, Caxias do Sul, v. 15, n. 1, p. 1 19-134, jan./abr. 2010.

LOURENÇÃO, Elizabeth Soares Pinheiro. Permanência e sucesso escolar de adolescentes autores de ato infracional: percepções do adolescente. 2015. $120 f$. Dissertação (Mestrado em Educação) - Programa de Pós Graduação em Educação, Universidade Estadual Paulista, Presidente Prudente, 2015.

MARCELO. Entrevista. (B, letra inicial da cidade). São Paulo, 28 jan. 2015.

MALVASI, Paulo Artur. Interfaces da vida loka: Um estudo sobre jovens, tráfico de drogas e violência em São Paulo. 201 2. 287f. Tese (Doutorado em Saúde Pública) - Programa de Pós Graduação em Saúde Pública, Universidade de São Paulo, São Paulo, 2012.

MONTEIRO, Regina Fernandes. Adolescentes em conflito com a lei: memórias e trajetórias de vivências na escola. 2010. 145f. Dissertação (Mestrado em Educação) - Programa de Pós-Graduação em Educação Universidade Federal do Pará, Belém, 2010.

PADOVANI, Andrea Sandoval; RISTUM, Marilena. A escola como caminho socioeducativo para adolescentes privados de liberdade. Educação e Pesquisa, São Paulo, v. 39, n. 4, p. 969-984, out./dez. 2013.

PARENTE, Cristiane. Comunidade, escola, jornal escolar: um estudo de caso. 2012. 49f. Dissertação (Mestrado em Educação) - Programa de Pós Graduação em Educação, Universidade de Brasília, Brasília, 2012.

PESSOA, Alex Sandro Gomes. Trajetórias negligenciadas: processos de resiliência em adolescentes com histórico de envolvimento no tráfico de drogas. 2015. 203f. Tese (Doutorado em Educação) - Universidade Estadual Paulista, Presidente Prudente, 2015.

ROCHA, Andrea Pires. Relações de trabalho no narcotráfico: exploração, riscos e criminalização. Argumentum, Vitória, v. 7, n. 1, p. 55-68, jan./jun. 2015.

Proibicionismo e a criminalização de adolescentes pobres por tráfico de drogas. Serviço Social e Sociedade, São Paulo, n. 115, p. 561-580, jul./set. 2013.

SANTOS, Rubenize Maria dos; NASCIMENTO, Maria Aparecida; MENEZES, Jaileila de Araújo. Os sentidos da escola pública para jovens pobres da cidade do Recife. Revista 
"traficante" não vai à escola: processos de escolarização de adolescentes com envolvimento no tráfico de drogas

Latinoamericana de Ciencias Sociales, Niñez y Juventud, Manizales (Colômbia), v. 10, n. 1, p. 289-300, 2012.

SILVA, Ivani Ruela de Oliveira; SALLES, Leila Maria Ferreira. Adolescente em liberdade assistida e a escola. Estudos de Psicologia, Campinas, v. 28, n. 3, p. 353-362, jul./set. 2011.

SILVA, Roberta Gassen da Silveira. A complexidade do fazer pedagógico: aprender na vivência das relações entre escola e comunidade. 2012. 98f. Dissertação (Mestrado em Educação) - Programa de Pós Graduação em Educação, Universidade de Santa Cruz do Sul, Santa Cruz do Sul, 2012.

SHOOK, Jeffrey; VAUGHN, Michael; GOODKIND, Sara; JOHNSON, Heath. An empirical portrait of youthful offenders who sell drugs. Journal of Criminal Justice, Ames, v. 39, n. 3, p. 224-231, maio./jun. 2011.

THIAGO. Entrevista. (B, letra inicial da cidade). São Paulo, 29 jan. 2015.

UNGAR, Michael. Playing at being bad: the hidden resilience of troubled teens. Toronto: Ontario Press, 2007.

UNGAR, Michael; BROWN, Marion; LIEBENBERG, Linda; OTHMAN, Rasha; KWONG, Wai-Man; ARMSTRONG, Mary. Unique pathways to resilience across cultures. Adolescence, 216 San Diego, v. 42, n. 166, p. 287-310, 2007.

UNGAR, Michael; LIEBENBERG, Linda; BOOTHROYD, Roger; KWONG, Wai-Man; LEE, Tak Yan; LEBLANC, John; DUQUE, Luis; MAKHNACH, Alexander. The study of youth resilience across cultures: lessons from a pilot study of measurement development. Research in Human Development, Philadelphia, v. 5, n. 3, p. 166-180, set. 2008.

UNGAR, Michael; LIEBENBERG, Linda; DUDDING, Peter; ARMSTRONG, Mary; VIJVER, Fons. Patterns of service use, individual and contextual risk factors, and resilience among adolescents using multiple psychosocial services. Child Abuse \& Neglect, Ontario, v. 37, n. 2, p. 150-159, fev./mar. 2013.

ZHANG, Dalun; Willson, Victor; KATSIYANNIS, Antonis; BARRET, David; JU, Song; JIUN-YU, Wu. Truancy offenders in the juvenile justice system: a multicohort study. Behavioral Disorders, Reston, v. 35, n. 3, p. 229-242, maio. 2010. 
Prof. Dr. Alex Sandro Gomes Pessoa

Universidade do Oeste Paulista (UNOESTE) Faculdade de Psicologia Programa de Pós Graduação em Educação Grupo de Pesquisa Educação, desenvolvimento humano em situação de risco e indicadores de proteção (UNESP - CNPq) Email | alexpessoa2@gmail.com

Prof. ${ }^{a}$ Dr. ${ }^{a}$ Renata Maria Coimbra Universidade Estadual Paulista (UNESP) Departamento de Educação Programa de Pós Graduação em Educação Líder do Grupo de Pesquisa Educação, desenvolvimento humano em situação de risco e indicadores de proteção (UNESP - CNPq) Email | coimbralibor@uol.com.br

Recebido 7 mar. 2015 Aceito 8 jun. 2016 